Marquette University

e-Publications@Marquette

$10-1-1998$

\title{
Investigating Equity Sensitivity as a Moderator of Relations Between Self-Efficacy and Workplace Attitudes
}

Bonnie S. O'Neill

Marquette University, bonnie.oneill@marquette.edu

Mark A. Mone

University of Wisconsin - Milwaukee

Accepted version. Journal of Applied Psychology, Vol. 83, No. 5 (October 1998): 805-816. DOI. (C) 1998 American Psychological Association. Used with permission.

This article may not exactly replicate the final version published in the APA journal. It is not the copy of record.

Bonnie S. O'Neill was affiliated with the University of Wisconsin-Milwaukee at the time of publication. 
Marquette University

e-Publications@Marquette

\section{Management Faculty Research and Publications/College of Business Administration}

This paper is NOT THE PUBLISHED VERSION; but the author's final, peer-reviewed manuscript. The published version may be accessed by following the link in th citation below.

Journal of Applied Psychology, Vol. 83, No. 5 (October 1998): 805-816. DOI. This article is (C) American Psychological Association and permission has been granted for this version to appear in ePublications@Marquette. American Psychological Association does not grant permission for this article to be further copied/distributed or hosted elsewhere without the express permission from American Psychological Association.

\section{Investigating Equity Sensitivity as a Moderator of Relations Between Self-Efficacy and Workplace Attitudes}

\section{Bonnie S. O'Neill}

School of Business Administration, University of Wisconsin-Milwaukee

\section{Mark A. Mone}

School of Business Administration, University of Wisconsin-Milwaukee

Acknowledgement: This study was conducted as part of Bonnie S. O'Neill's master's thesis, completed under the supervision of Mark A. Mone. We are grateful to Paul Nystrom for his comments on previous drafts of this article.

Several reviews have indicated that relationships between job satisfaction and the related outcomes of organizational commitment and intention to leave an organization are among the most frequently examined issues in organizational literature (e.g., DeCotiis \& Summers, 1987; Farkas \& Tetrick, 
1989; Mathieu \& Zajac, 1990; Meyer \& Allen, 1997; Mowday, Porter, \& Steers, 1982; Randall, 1987; Reichers, 1985; Tett \& Meyer, 1993; Wanous, Reichers, \& Hudy, 1997). More than 2 decades ago, for example, Locke (1976) noted the existence of more than 3,350 studies on job satisfaction. More recently, Spector (1997, p. 1) contended that job satisfaction is "the most frequently studied variable in organizational behavior research." This body of research demonstrates that more satisfied employees usually experience greater affective commitment (Locke \& Latham, 1990a; Mathieu, 1991; Meyer \& Allen, 1997) and that more committed employees are less likely to leave voluntarily (e.g., Allen \& Meyer, 1990; Hom \& Griffeth, 1995; Mowday et al., 1982). There is also evidence that satisfied, committed employees are associated with better organizational performance (Ostroff, 1992).

Although correlations among these variables are consistent and statistically significant, there remains considerable unexplained variability in these relationships. For example, Mathieu and Zajac's (1990) meta-analysis of 43 studies reported an average correlation of .53 between job satisfaction and organizational commitment, after correcting for sampling error and measurement unreliability. Likewise, correlations between satisfaction and intent to leave have been found to approach, but not usually exceed, .40 (e.g., Locke, 1976, p. 1331). Given the sizeable body of research and the remaining unexplained variance in these variables, there appears to be a need to better identify common factors affecting job satisfaction, organizational commitment, and intent to leave. Such research may subsequently contribute to our understanding of relations between these variables.

In the following paragraphs, we draw from two theoretical perspectives, social cognitive theory (Bandura, 1986) and equity theory (Adams, 1965), that offer useful points of integration for better understanding such work-related attitudes and outcomes. Specifically, we propose that relations between one aspect of personality-self-efficacy-and job satisfaction, organizational commitment, and intent to leave are moderated by another personality dimension-equity sensitivity. Self-efficacy, a central component of social cognitive theory, is task-specific self-confidence (Bandura, 1997); equity sensitivity is an individual difference that involves sensitivity to overreward or underreward situations. The premise underlying our integration of these components is that whereas self-efficacy influences individuals' perceptions of capabilities and task persistence, equity sensitivity governs reactions to situations of inequity and perceived desirability of subsequent efforts. It is our contention that job satisfaction, organizational commitment, and intent to leave are not formed in a vacuum within the individual but, rather, develop through work experiences and comparisons with others in the workplace. We further contend that there is considerable variation in the extent to which people develop competency perceptions and in the degree to which people use and are affected by comparisons with others. By synthesizing key components from these social comparison perspectives, we seek to add to knowledge of how and why individuals facing similar social exchange situations react differently.

Equity sensitivity and self-efficacy were chosen partially because of their centrality in their respective theories. Additionally, both constructs have received increasing attention as variables that extend the theoretical and practical bases of the social comparison processes from which they derive (Bandura, 1997; Huseman, Hatfield, \& Miles, 1987; King \& Miles, 1994). As described below, there are also compelling arguments that can be developed for how different combinations of equity sensitivity and self-efficacy may extend both equity and social cognitive theories. In so doing, we may be able to 
explain more variability in job satisfaction, organizational commitment, and intent to leave. This latter goal is a fundamental objective of much work in organizational studies, and it is toward this end that we hope to offer insights from which both managers and researchers may benefit.

Equity theory, rooted in social comparison processes (e.g., Festinger, 1954), is concerned with how individuals compare their ratio of inputs and outcomes relative to the same ratio of comparison others. On the basis of such comparisons, equity theory offers predictions about how individuals will react to overreward and underreward situations (cf. Adams, 1965; Pritchard, Dunnette, \& Jorgenson, 1972). Potential reactions generally concern individuals' level of satisfaction and their anticipated future task effort levels. Although at one time equity theory was hailed as being among the foremost middle-range motivation theories (Weick, 1966), several reviewers later noted its inability to differentiate who would react in the manner prescribed by its notions (Major \& Deaux, 1982; Miner, 1980; Mowday, 1991). Recently, however, equity theory has resurfaced as a theoretical basis underlying research in organizational justice and rewards (Greenberg, 1990), survivor guilt (Brockner et al., 1986), and individual differences in justice behavior (Brockner, 1985).

One of the reasons that equity theory has received increasing attention is because of the development of the equity sensitivity construct, which has increased the predictive utility of the theory (King \& Miles, 1994; King, Miles, \& Day, 1993). Equity sensitivity is an individual difference that characterizes how individuals react to situations perceived to be equitable or inequitable. The equity sensitivity continuum is commonly divided into three different types of equity-sensitive people (e.g., Huseman et al., 1985, 1987): Originally, benevolents were defined as individuals who preferred their outcome-input ratio to be less than those of comparable others; however, recent findings suggest benevolents may simply have more tolerance for underreward (King et al., 1993). As noted in literature on altruism, these people may be considered "givers" (Hatfield \& Sprecher, 1983). Past research suggests that, for benevolents, being on the receiving end of a social exchange is extremely aversive, whereas being a donor or "creditor" is highly pleasant (Greenberg \& Westcott, 1983; Huseman et al., 1985). At the other extreme, entitled individuals prefer their outcomes to exceed their inputs relative to others. It is argued that entitleds' contentment derives from perceptions that they are "getting a better deal" than those around them, and they are not satisfied unless this is the case; such individuals have been characterized as "getters." In between these two extremes are individuals termed equitysensitive. These individuals are thought to be those described by traditional equity theory precepts, seeking to balance their outcome-input ratio with those of others so as to avoid both underreward and overreward situations.

Recent empirical work examining the equity sensitivity construct has found it to increase the explanatory power of equity theory. Several studies have demonstrated that equity sensitivity predicts the different reactions experienced by people in similar inequity situations reasonably well (Huseman et al., 1985; King et al., 1993; Miles, Hatfield, \& Huseman, 1989; Patrick \& Jackson, 1991). Specifically, benevolent individuals have been found to be more satisfied, relative to entitled and equity-sensitive individuals, in situations of underreward (King \& Miles, 1994; Miles, Hatfield, \& Huseman, 1994). Likewise, in situations of overreward, entitleds have been found in this research to experience more satisfaction than benevolents or equity-sensitives. Miles et al. (1989) have even argued that because benevolents are willing to work harder and longer for less, managers may want to consider the staffing 
implications of such findings. The study of equity sensitivity has also been extended to other outcomes on a limited basis. For example, in a recent validation study of an equity-sensitivity instrument (King \& Miles, 1994), equity sensitivity was shown to correlate positively (i.e., higher scores were more benevolent) with job satisfaction and organizational commitment and negatively with intent to leave.

Given the extensions made to equity theory by the integration of equity sensitivity, perhaps work attitudes can be even better predicted by taking into consideration other individual differences. Social cognitive theory (Bandura, 1986) proposes an elaborate causal structure that comprehensively explains both competency development and regulation of action. This theory is the latest expansion of Bandura's (1977) social learning theory, and it deals with, among other things, perceptions of how capable individuals believe they are for performing various activities and the efforts promulgated and persisted in by such beliefs. Self-efficacy is a critical component of social cognitive theory because it is a primary influence on human thought, motivation, and action (Bandura, 1997, p. 34). Applications in organizational literature have demonstrated consistently that self-efficacy positively predicts personal goals, task learning, direction and persistence of effort, task performance levels, and attributions made for performance levels (e.g., Bandura, 1997; Button, Mathieu, \& Aikin, 1996; Gist, 1987; Locke \& Latham, 1990a; Mone, 1994a, 1994b; Mone \& Baker, 1992; Wood \& Locke, 1987).

Although social cognitive theory aids in the potential understanding of a broad range of work-related attitudes and behaviors (e.g., vocational choice, task persistence), only limited empirical work has examined self-efficacy in relation to job satisfaction, organizational commitment, or intention to leave. A recent study by Mone (1994a) examined a model of self-efficacy, self-esteem, and goals in relation to these variables in a downsizing organization. As in other studies (e.g., Locke, Frederick, Lee, \& Bobko, 1984; Wood \& Locke, 1987), Mone found that self-efficacy significantly predicted goals; however, extending past work, he found that in a downsizing organization, self-efficacy was positively related to intention to leave, suggesting that in such situations, those who consider themselves more capable may seek and be able to find work elsewhere. He additionally found that self-efficacy was inversely related to job satisfaction and organizational commitment, suggesting that in a downsizing organization, higher self-confidence and performance are not necessarily met with the commensurate rewards and job security that help create job satisfaction and affective commitment.

Although both research streams provide preliminary evidence hinting at relations with workplace attitudes, what both equity sensitivity and self-efficacy research have left unexplained is how these constructs may interact to affect job satisfaction, organizational commitment, and intention to leave. Given the importance of these attitudes, there are several provocative questions that may be further examined by considering possible areas of conceptual overlap. At the simplest level, what is the likely relationship between equity sensitivity and self-efficacy? Is it possible, for example, that as individuals become more confident, they come to feel more entitled? If so, does this finding suggest that organizational rewards must increase in order to retain valued senior employees, beyond the value added by their increased experience? Alternatively, if equity sensitivity is a trait (as suggested by equity sensitivity proponents; e.g., Huseman et al., 1987), then perhaps, despite the level of self-efficacy, certain feelings of entitlement or discomfort with overreward exist independent of job tenure. However, we suggest that the effects are more complex than simply the main or direct effects of equity sensitivity and self-efficacy. It is our contention that different combinations of self-efficacy and 
equity sensitivity have different effects on subsequent reactions to social exchange situations. More specifically, we argue that equity sensitivity moderates relations between self-efficacy and job satisfaction, organizational commitment, and intent to leave.

\section{Job Satisfaction}

We view job satisfaction in a manner similar to that of Locke (1976, p. 1300), who described it as "a pleasurable or positive emotional state resulting from the appraisal of one's job or job experiences." We hypothesize that the relationship between self-efficacy and job satisfaction should be at least partially conditioned upon the degree of equity sensitivity one possesses. Social cognitive theory suggests that self-efficacious individuals set high goals, perform at high levels, and receive commensurate recognition and rewards (Bandura, 1986; Locke \& Latham, 1990b), from which they may experience higher job satisfaction than their low-self-efficacy counterparts. Research also shows that individuals low in self-efficacy set lower goals and experience lower performance relative to those with high self-efficacy (Barling \& Beattie, 1983; Locke et al., 1984). In turn, individuals setting lower goals and achieving lower performance levels generally receive lower rewards and have more limited career opportunities than their higher performing counterparts (Locke \& Latham, 1990b).

We propose that equity sensitivity moderates the relation between self-efficacy and job satisfaction in the following manner: Those low in self-efficacy and with a greater sense of entitlement are likely frustrated with the levels of recognition they receive for their efforts, relative to benevolents. Past research has suggested that individuals with lower self-efficacy generally have lower aspiration levels, acquire fewer marketable skills, and may be less inclined to engage in job search (Bandura, 1997; Betz \& Hackett, 1986; Mone, 1994a). Yet, even assuming similar reward structures for all, entitled individuals may still expect more (i.e., greater rewards) from their jobs than benevolent individuals with low self-efficacy. Furthermore, low-self-efficacy benevolent individuals by definition may simply be more grateful than their low-self-efficacy entitled counterparts. Consequently, relative to entitled individuals with low self-efficacy, benevolents with low self-efficacy are likely to experience more job satisfaction.

On the other hand, entitleds with high self-efficacy likely set higher goals and perform at higher levels than their low-self-efficacy counterparts. Because of their entitlement mentality, they may not experience the reward levels they would like to receive; however, we argue that entitleds with high self-efficacy are in positions that allow them to receive more recognition and rewards and are likely to have wider career choices, and consequently to be more satisfied than their low-self-efficacy entitled counterparts. In essence, those who are self-confident and entitled are more likely to find and develop vocational opportunities in which they can experience job satisfaction than those who are entitled but lack the confidence to attain mastery of their work situations. Supporting our contention is the almost universal finding of a positive relationship between job level and job satisfaction (e.g., Locke, 1976).

As for benevolents with high self-efficacy, we suspect that they, too, experience job satisfaction as a result of occupying more rewarding occupations and having greater task mastery. However, we propose that the moderating effect of equity sensitivity is to lessen the satisfaction of benevolents with high self-efficacy relative to those low in self-efficacy. High self-efficacy usually results from having attained task mastery over repeated performance experiences (Bandura, 1997). We expect that 
benevolent individuals with high self-efficacy are accustomed to more positive reinforcement than their low-self-efficacy counterparts. Hence, they may have higher expectations and relatively less job satisfaction than low-self-efficacy benevolents. Additionally, given the higher job satisfaction to begin with for low-self-efficacy benevolents, there may be a less positive moderating effect for those higher in self-efficacy. These arguments suggest the following hypothesis:

Hypothesis 1. Equity sensitivity moderates the relation between self-efficacy and job satisfaction so that for benevolent individuals there is a more negative relation than for entitled individuals.

\section{Organizational Commitment}

Although organizational commitment can be viewed as multidimensional (Meyer \& Allen, 1997), the dimension we consider most relevant for our purposes is psychological attachment to the organization. This type of commitment has been described as affective commitment and has been differentiated from continuance and normative types of commitment (see reviews by Meyer \& Allen, 1997; Meyer, Allen, \& Gellatly, 1990). Affective commitment is commonly employed in studies examining job satisfaction and withdrawal cognitions (e.g., Allen \& Meyer, 1990; Irving, Coleman, \& Cooper, 1997; Mathieu \& Zajac, 1990; Mone, 1994a). Our premise is that those higher in self-efficacy are generally more committed to the organization because they have more confidence to pursue career challenges (Lent \& Hackett, 1987), from which they are likely to receive greater organizational returns. We contend that those high in self-efficacy pursue higher goals, achieve more in their work, and experience more satisfaction that fosters organizational commitment.

However, we expect that the relationship between self-efficacy and organizational commitment is moderated by equity sensitivity in a manner similar to that of the self-efficacy-job satisfaction relation. We argue that more benevolent individuals with low self-efficacy may feel greater affective commitment to their employers out of a sense of gratitude than more entitled low-self-efficacy individuals. However, among those high in self-efficacy, we suspect that organizational commitment is increased for both entitleds and benevolents. Past research has demonstrated that a critical determinant of self-efficacy is positive mastery experiences (Bandura, 1986). Likewise, considerable research has demonstrated how those high in self-efficacy set higher goals and achieve greater task performance levels. Accordingly, we assert that high self-efficacy individuals are more likely to be in career situations in which they possess greater organizational commitment than those low in selfefficacy. As for those who are low in self-efficacy and entitled, their entitlement expectations may help offset their low self-confidence to the point where they do not feel the same level of affective commitment to their employers. Conversely, entitled individuals who are higher in self-efficacy may well experience more of the rewards, recognition, and career opportunities that increase appreciation and affective commitment to their employers.

Both entitleds and benevolents who are high in self-efficacy are more likely to have realized past performance mastery experiences from which they have gained access to more occupational choices. It is also possible that they not only have found more satisfactory occupational niches, but also may feel more committed to organizations that currently provide them with these experiences. As is consistent with our argument, Mathieu and Zajac's (1990) meta-analysis found that competency perceptions were positively related to affective commitment. Additionally, benevolents and entitleds with high self- 
efficacy may be appreciative of the rewards and recognition they receive and subsequently may be more likely to feel affectively committed to the organization. For these reasons, we suggest the following hypothesis:

Hypothesis 2. Equity sensitivity moderates the relation between self-efficacy and organizational commitment so that for benevolent individuals there is a more negative relation than for entitled individuals.

\section{Intent to Leave}

Intent to leave has been identified as the most immediate psychological precursor to actually leaving an organization (Hom \& Griffeth, 1995; Mobley, 1977; Mobley, Horner, \& Hollingsworth, 1978). Our analysis of the relationship between self-efficacy and intent to leave as moderated by equity sensitivity draws directly from the logic used to explicate the previous relationships. As was argued for Hypotheses 1 and 2, we first contend that more benevolent low-self-efficacy individuals experience more job satisfaction and greater organizational commitment than their entitled low-self-efficacy counterparts. Consequently, given their higher anticipated levels of job satisfaction and organizational commitment, we expect that benevolents low in self-efficacy should be less likely to leave than their entitled counterparts.

Individuals low in self-efficacy typically have lower confidence, less developed skills, and fewer task mastery experiences than high-self-efficacy individuals (Bandura, 1997). Accordingly, those lower in self-efficacy may not achieve the same levels of rewards and career choices as those high in selfefficacy (Betz \& Hackett, 1986). Whereas for benevolent individuals such a situation may be tolerable (e.g., King et al., 1993), for entitleds it is likely frustrating and may foster intent to leave. To the extent that rewards and recognition are congruent with values, George and Jones's (1996) work, finding that individuals who do not attain values in the workplace are more inclined to leave, corroborates our perspective. We also note that, consistent with our earlier hypotheses, low-self-efficacy entitled individuals are the most likely to be dissatisfied and least committed.

Meanwhile, low-self-efficacy benevolents, while experiencing the same relatively low levels of skill acquisition and mastery experiences, are, by definition, more passive or acquiescent when faced with underreward situations. And, underscoring this argument, low-self-efficacy individuals who are more benevolent may not perceive their situation as one of underreward. Hence, relative to low-self-efficacy benevolents, low-self-efficacy entitleds are likely to react more negatively and be more inclined to leave.

As for those higher in self-efficacy, past research suggests that they have greater task confidence, more mastery experiences, more skill proficiencies, and more history of organizational and career opportunities (Betz \& Hackett, 1986; Gist, 1987). We expect that those with higher self-efficacy also have developed higher expectations than those low in self-efficacy, as befit their higher abilities. We expect that both entitleds and benevolents high in self-efficacy have developed these higher expectations. However, because entitleds low in self-efficacy already expect more than their benevolent counterparts, there probably is little difference in entitleds across the low- to high-selfefficacy continuum. In contrast, relative to the expectations of low-self-efficacy benevolents, high-selfefficacy benevolents may be markedly higher in their expectations. Correspondingly, they may feel a 
greater intent to leave, all else being equal, than low-self-efficacy benevolents, who may be more satisfied, committed, and grateful to the organization. These arguments suggest the following hypothesis:

Hypothesis 3. Equity sensitivity moderates the relation between self-efficacy and intent to leave so that for benevolent individuals there is a more positive relation than for entitled individuals.

\section{Method}

\section{Participants}

Participants were 242 employees in a mid-sized (i.e., 560 employees) health care service organization located in the Midwest. The response rate was $43 \%$, and respondents represented fairly evenly the distribution of occupations throughout the organization (e.g., nurses, physicians, laboratory technicians, researchers). Of the respondents, $78 \%$ were female, and the average age of respondents was 38 (ranging from 18 to 65+). The sample closely represented the overall organization population, which was $75 \%$ female, with the average employee being 36 years old. Respondents' educational background ranged from those with a minimum of a high school diploma to an MD and/or a PhD, with the median response being some graduate course work, but no graduate degree.

\section{Procedure}

After securing support for the research from the firm's top management, we distributed a survey to all employees via interoffice mail. A cover letter explained the general purpose of the project, and a postage-paid, pre-addressed envelope for returning the completed survey to an off-site university location was also included. A reminder postcard was sent to all employees 3 weeks later. Employees were allowed to complete the survey on work time, participation was voluntary, and anonymity was promised.

\section{Measures}

\section{Equity sensitivity}

Each participant's equity sensitivity was measured by use of Huseman et al.'s (1985) Equity Sensitivity Instrument (ESI). This five-item, forced-distribution scale measures responses on a continuum from benevolent to entitled, on the basis of 10 points assigned between two statements. An example item was "It would be more important for me to: A. Help others. B. Watch out for my own good." Scores can range from 0 to 50; they are the sum of points allocated to the benevolent statement in each of the five items (with 50 being highly benevolent and 0 being highly entitled). Previous test results have yielded a coefficient alpha of .83 for the ESI (Huseman et al., 1985) and a test-retest reliability of .80 (Miles et al., 1989). For this study, Cronbach's coefficient alpha was .86 ( $M=$ $30.18, S D=7.16)$. Whereas past research has trichotomized equity sensitivity into three distinct groups, we employed the entire ESI scale, considering it a continuous measure.

\section{Job satisfaction}

Overall job satisfaction was measured by use of an 18-item scale developed by Brayfield and Rothe (1951). Responses are scored 1 (strongly agree) to 5 (strongly disagree) and summed, yielding a possible range of scores between 18 and 90 . Half of the items are reverse-scored. Brayfield and Rothe 
intended the measure to be "applicable to a wide variety of jobs" (Cook, Hepworth, Wall, \& Warr, 1981, p. 17). Items included "I consider my job rather unpleasant," "I am often bored with my job," "I feel fairly well satisfied with my present job," and "I find real enjoyment in my work." Cronbach's coefficient alpha for this scale was .91.

\section{Organizational commitment}

Organizational commitment was measured by the Affective Commitment Scale (ACS) developed by Allen and Meyer (1990). The overall organizational commitment scale gathered responses ranging from 1 (strongly disagree) to 7 (strongly agree) to assess employees' perceptions of commitment to the organization by representing their sense of "belonging" to the organization. Responses on the scale, which were averaged, measured emotional attachment to the organization (e.g., "I do not feel a strong sense of belonging to my organization," "I do not feel 'emotionally attached' to this organization"). This four-item scale for organizational commitment had a Cronbach's coefficient alpha of .87 .

\section{Self-efficacy}

Self-efficacy was assessed on eight subscales by use of methodology suggested by Bandura (1986) and Wood and Bandura (1989). The subscales assessed employees' level of task-related confidence ( 0 = totally unconfident to $9=$ totally confident) at four increasing levels of mastery $(50 \%$, $70 \%, 90 \%$, and $100 \%$ ) on the following eight essential job duties: standard operating procedures; reading and understanding of facts, concepts, and technical information; technology; explaining concepts; internal communication; external communication; problem solving; and creativity/innovation. The content of the subscales was generated by identifying common core tasks from job descriptions used throughout the organization. As is consistent with past self-efficacy validation studies (e.g., Mone, 1994b; Wood \& Locke, 1987), combining subscales from common domains across organizational occupations created a self-efficacy scale that captured variability in job duties while simultaneously allowing comparisons across many organizational positions. Sample items (e.g., problem solving, creativity/innovation) included "The degree to which you feel you are able to successfully resolve problems on your own within your own department" and "The degree to which you are comfortable coming up with and presenting new and creative ideas for your department." Average confidence ratings were used across all subscales. Subscale Cronbach coefficient alphas ranged from .79 to .92 , and the coefficient alpha for the overall 32-item self-efficacy scale was .81 . Given the acceptably high subscale and overall scale alphas, we averaged the subscale means to create a single self-efficacy score.

\section{Intent to leave}

Employees' intent to leave the organization was assessed by use of a single-item scale that asked employees to mark their answer on a 4-point scale ranging from I intend to stay until I retire (1) to I intend to leave as soon as possible (4). This measure has been found to be significantly negatively correlated with organizational tenure ( $r$ value of -.80 ) (Ferris \& Rowland, 1987).

Personal goals, effort, and performance Although personal goals, effort, and performance were not included in the hypotheses, they were controlled statistically in this study, because past studies have found them to correlate highly with the 
relationships under investigation (cf. Button et al., 1996; Locke \& Latham, 1990a, 1990b; Mone, 1994a). Personal goals were measured with four items adapted from Locke and Latham (1990a, pp. 355-358), with responses ranging from 1 (almost never) to 5 (almost always). Example items included "I have deadlines for accomplishing my goals on this job" and "I have specific, clear goals to aim for on my job." Cronbach's coefficient alpha for this scale was .79. Effort was assessed with a single-item scale ranging from 1 (never) to 5 (always), which asked: "I can usually sustain a high level of effort in performing my work tasks." A five-item scale developed by S. J. Ashford (personal communication, August 4,1995 ) was used to assess employees' perceptions of their performance in the organization. Responses ranged from 1 (strongly disagree) to 7 (strongly agree) on items such as "The quality of my work is seen as excellent by others in this organization" and "I have a reputation in this organization for doing my work very well." Cronbach's coefficient alpha was .93. Mean scores were used for goals and performance. Because they might be correlated with the dependent variables, we also controlled for age, sex, and education level.

\section{Results}

The means, standard deviations, interitem reliabilities, and correlations are reported in Table 1. As is consistent with past research, job satisfaction and organizational commitment were positively correlated with each other, and both were negatively correlated with intent to leave. Equity sensitivity was positively correlated with self-efficacy, job satisfaction, and organizational commitment, and negatively correlated with intent to leave. Self-efficacy was not significantly correlated with job satisfaction, organizational commitment, or intent to leave.

Table 1. Means, Standard Deviations, Interitem Reliabilities, and Pearson Correlations

\begin{tabular}{|c|c|c|c|c|c|c|c|c|c|c|c|c|}
\hline $\begin{array}{c}\mathrm{b} \\
\mathrm{a} \\
\mathrm{r} \\
\mathrm{i} \\
\mathrm{a} \\
\mathrm{b} \\
\mathrm{l} \\
\mathrm{e} \\
\end{array}$ & $M$ & $S D$ & I & 2 & 3 & 4 & 5 & 6 & 7 & 8 & 9 & 10 \\
\hline I. Age' & 6.05 & 2.15 & & & & & & & & & & \\
\hline 2. Sex' & 0.21 & 0.41 & -.04 & & & & & & & & & \\
\hline 3. Education levelc & 6.42 & 1.97 & $-.30 * *$ & $.17^{*}$ & & & & & & & & \\
\hline 4. Goals & 3.94 & 0.81 & .01 & -.11 & .06 & .79 & & & & & & \\
\hline 5. Effort & 4.14 & 0.58 & .07 & .01 & .00 & $.28^{* *}$ & & & & & & \\
\hline 6. Performance & 5.33 & 1.07 & .10 & -.08 & -.05 & $.38^{* *}$ & $.27^{* *}$ & .93 & & & & \\
\hline 7. Equity sensitivity & 30.18 & 7.16 & $.16^{*}$ & -.09 & $\begin{array}{l}- \\
.24 * * \\
\end{array}$ & $.19 * *$ & $.14^{*}$ & $\begin{array}{l}.14^{*} \\
.86 \\
\end{array}$ & & & & \\
\hline 8. Self-efficacy & 7.46 & I.IO & .06 & .05 & -.02 & $.21^{* *}$ & $.22 * *$ & $.21^{* *}$ & $.15^{*}$ & .81 & & \\
\hline 9. Job satisfaction & 3.66 & 0.57 & $.18^{* *}$ & $-.18^{* *}$ & .06 & $.40 * *$ & .II & $.32 * *$ & $.28^{* *}$ & -.01 & $\begin{array}{l}.9 \\
1\end{array}$ & \\
\hline $\begin{array}{l}\text { 10. Organizational } \\
\text { commitment }\end{array}$ & 4.66 & 1.65 &. $\mathrm{IO}$ & $-.15 *$ & $-.14^{*}$ & $.25^{* *}$ & $\begin{array}{l}0 \\
7\end{array}$ & $.32 * *$ & $.30^{* *}$ & .03 & $.58^{* *}$ & .87 \\
\hline 11. Intent to leave & 2.17 & 0.80 & $-.48 * *$ & .11 & $\begin{array}{l}.38 * \\
*\end{array}$ & $.20 \star \star$ & -.02 & $-.16 *$ & $.30^{* *}$ & -.03 & $-.49 * *$ & $\begin{array}{c}- \\
.45 * \\
*\end{array}$ \\
\hline
\end{tabular}

Note. Interitem reliabilities (Cronbach's alpha) are on the diagonal $(N=224-242)$.

a Age was divided into 12 categories in approximately 5 -year increments ( $I=$ under 18 years of age; $12=$ over 65 years of age). $\mathrm{b}$ Sex was coded $0=$ female and $\mathrm{I}=$ male. 'Educati, level was divided into 11 categories $(0=$ less than high school diploma; $10=$ PhD or equivalent $)$.

$* p<.05 . * * p<.01$. 
Hierarchical moderated regression equations were used to test the hypotheses and to control statistically for age, sex, education, personal goals, effort, and self-reported performance levels. Specifically, we sought to examine the moderating effect of equity sensitivity on self-efficacy and each outcome variable: job satisfaction, organizational commitment, and intent to leave. Following Cohen and Cohen (1983), for each hypothesis, we entered age, sex, education, personal goals, effort, and performance as control variables in the regression equation. Then, we entered the main effects for hypothesized variables, followed by their cross-product interaction terms. Pairwise deletion of missing data was used, resulting in a useable sample of 218 respondents.

The first regression equation examined Hypothesis 1, concerning the proposed moderating effects of equity sensitivity on the relationship between self-efficacy and job satisfaction. As reported in Table 2 , the interaction term was significant $(\beta=-.02, p<.01)$ and in the predicted direction. By partialling out the cross-product term, we were able to identify an incremental change in $R^{2}$ of 0.03 , which is statistically significant at $p<.01$. The nature of the interaction was determined by plotting the relation between self-efficacy and job satisfaction at high and low levels of equity sensitivity (i.e., using one standard deviation above and below the mean). Figure 1 demonstrates that for more benevolent individuals, there was a stronger negative relation between self-efficacy and job satisfaction, supporting Hypothesis 1.

Table 2. Hierarchical Regression Results for Variables Predicting Job Satisfaction, Organizational Commitment, and Intent to Leave $(N=220)$

\begin{tabular}{|c|c|c|c|c|c|c|}
\hline & \multicolumn{2}{|c|}{ Job satisfaction } & $\begin{array}{l}\text { Organizational } \\
\text { commitment }\end{array}$ & \multicolumn{2}{|c|}{ Intent to leave } & \\
\hline Predictor variable & $(3$ & $b . R^{\prime}$ & $(3$ & $b . R^{\prime}$ & $(3$ & $b . R^{\prime}$ \\
\hline Step I & & $.23^{* *}$ & & $.15^{* *}$ & & $.35 * *$ \\
\hline Sex &,- 14 & & -.32 & & .00 & \\
\hline Age & .03 & & .02 & & $-.13 * *$ & \\
\hline Education level & .00 & & -.05 & & $.10^{* *}$ & \\
\hline Goals & $.25 * *$ & & .26 & & $-.23 * *$ & \\
\hline Effort & -.01 & & -.17 & & .09 & \\
\hline $\begin{array}{l}\text { Performance } \\
\text { Step } 2\end{array}$ & $.12^{* *}$ &. $\mathrm{OS} \bullet \bullet$ & $.40 * *$ & $.05 * *$ & -.05 & $.02 *$ \\
\hline Self-efficacy (SE) &, $36 * *$ & & -.06 & & $-.57 * *$ & \\
\hline Equity sensitivity (ES) & $.13^{* *}$ & & .07 & & $-.18 * *$ & \\
\hline Step 3 & & $.03^{* *}$ & & .00 & & $.03^{* *}$ \\
\hline SEX ES & $-.02 \bullet \bullet$ & & .00 & & $.02 \bullet \bullet$ & \\
\hline
\end{tabular}

Overall $\boldsymbol{F}$ for equation $10.44 * * 5.85 * * 15.62 * *$

Note. (3 is the standardized regression coefficient from the full regression equation with all predictor variables. Increments for variables entered at the, $6 . \mathrm{R}^{2}$ significance Jevels are based on $F$ test" for that step. ${ }^{*} p<, 05 .{ }^{* *} p<.01$. 


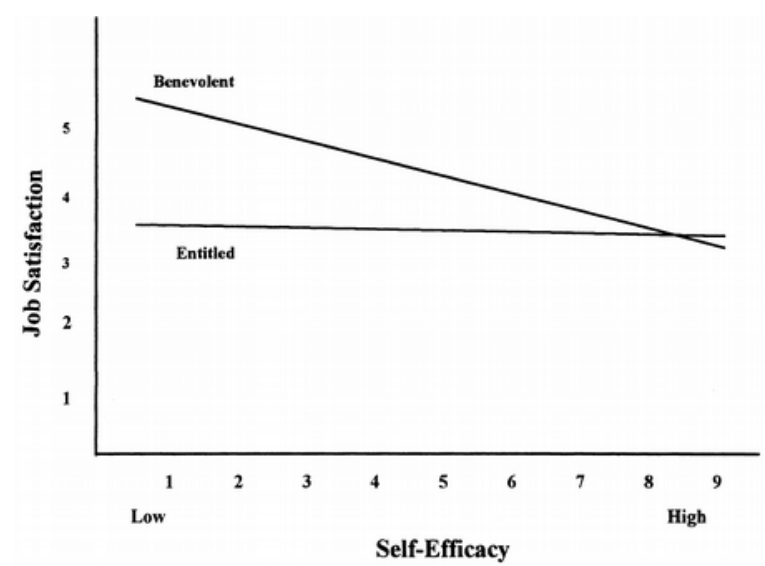

Figure 1. Equity sensitivity as a moderator of self-efficacy and job satisfaction

The second regression equation examined Hypothesis 2, which involved the moderating effects of equity sensitivity on the relation between self-efficacy and organizational commitment. As reported in Table 2 , the interaction term was not significant $(\beta=-.002, n s)$, and there was no significant incremental change in $R^{2}$. The main effects for self-efficacy and equity sensitivity were also not significant.

The third regression equation examined Hypothesis 3, involving the moderating effect of equity sensitivity on the relationship between self-efficacy and intent to leave. The equity sensitivity-selfefficacy interaction term was significant $(\beta=.02, p<.01)$, as reported in Table 2 , supporting the hypothesized relations. In this step, the incremental change in $R^{2}$ was found to be 0.03 , significant at $p<.01$. The resulting graph, after solving the equation for representative values of equity sensitivity and self-efficacy, is shown in Figure 2. This figure demonstrates that, for benevolent individuals, there was a greater positive relationship between self-efficacy and intent to leave, as proposed in Hypothesis 3.

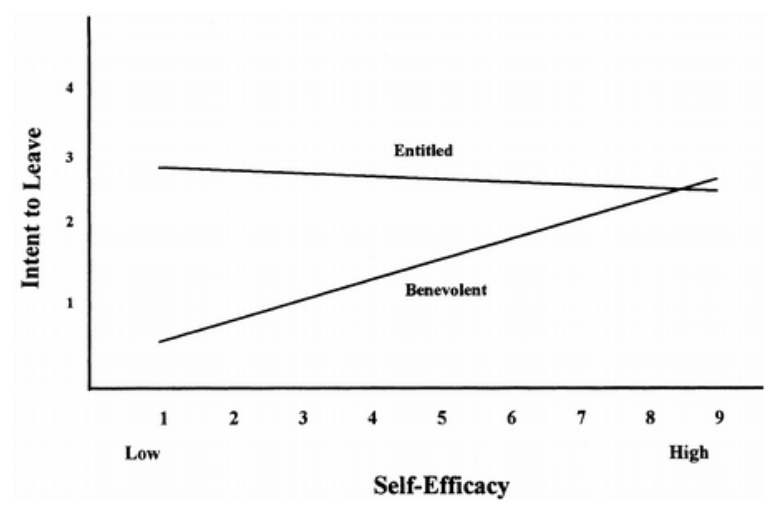

Figure 2. Equity sensitivity as a moderator of self-efficacy and intent to leave

\section{Discussion}

This study sought to advance knowledge concerning how equity sensitivity moderates relationships between self-efficacy and job satisfaction, organizational commitment, and intent to leave. Only limited past research has addressed these outcomes in relation to self-efficacy, and no previous 
research to our knowledge has examined the interactive effects of self-efficacy and equity sensitivity. Our core findings are that among more benevolent individuals, there is a greater negative relationship between self-efficacy and job satisfaction than among entitled individuals. Additionally, more benevolent individuals experience a stronger positive relationship between self-efficacy and intent to leave. The hypothesized moderating effect of equity sensitivity on the relation between self-efficacy and organizational commitment was not found. The following section discusses implications, directions for future research, and possible limitations of this study.

The finding of moderating effects here extends our understanding of how individual differences can improve the prediction of job satisfaction and the related outcome of intent to leave. The distinctive findings in our research concern benevolents, for whom there exist a negative relation between selfefficacy and job satisfaction and a positive relation between self-efficacy and intent to leave. Although internally consistent, these findings are somewhat at odds with the generally positive effects found in past literature on self-efficacy. For example, past research has identified potential learning and productivity benefits accruing from self-efficacy training, in addition to other positive individual and organizational outcomes (e.g., Bandura, 1997; Gist, 1987; Gist, Stevens, \& Bavetta, 1991; Locke \& Latham, 1990a, 1990b; Mone \& Baker, 1992). However, we found that those at low and moderate levels of self-efficacy had higher amounts of job satisfaction and lower intent to leave than those with high self-efficacy. Hence, in congruence with Mone's (1994a) findings, simply increasing self-efficacy alone may not lead to increased job satisfaction or reduced intent to leave among employees. Rather, it may be necessary to provide additional career opportunities, redesign work, or alter organizational recognition and reward systems. These findings do not negate the overall positive influence of individuals' self-efficacy on organizations; rather, they extend our understanding of potential concerns that may pertain if additional outcomes (e.g., job satisfaction, intent to leave) are not considered and if other individual differences (e.g., equity sensitivity) are ignored.

Examining the interactive effects of equity sensitivity and self-efficacy on workplace attitudes also extends the domain of equity and social cognitive theories. It appears that perceptions of competency and sensitivity to equity not only are relevant in determining attitudes toward past and present experiences, but also are especially salient in determining future actions. Although past research has examined self-efficacy in these relations to a limited extent (e.g., Mone, 1994a), this study illustrates the value of going beyond main effects. Indeed, our findings raise the possibility that different combinations of self-efficacy and equity sensitivity are applicable to a host of behavioral outcomes related to job satisfaction, affective commitment, and intention to leave. Future longitudinal research might examine, for instance, the behavioral consistency between the different levels of intent to leave found in our study. Specifically, do high-self-efficacy entitled individuals who intend to leave actually leave at a faster rate than low-self-efficacy entitled individuals who intend to stay? Numerous other behavioral outcomes could be examined, including workplace attendance, absenteeism, tardiness, citizenship behaviors, theft, and so forth.

Given the internal consistency in our hypothesized moderating effects of equity sensitivity, it may be useful to discuss the lack of support found for the moderating role of equity sensitivity in the selfefficacy-organizational commitment relationship. One possible explanation is that the correlation between equity sensitivity and organizational commitment is so substantial that it mitigates against 
any moderating effect. That is, in our sample, benevolents consistently reported greater organizational commitment, independent of self-efficacy, than entitleds; because sample specificity is a distinct possibility, additional research appears necessary. Another possible explanation for this finding is that the affective organizational commitment measure was not sensitive enough to gauge the actual variability that may be related to equity sensitivity and self-efficacy. For our purposes, this seemed to be the appropriate measure; however, future research may benefit by exploring additional dimensions of commitment (e.g., normative, continuance) and also by employing other measures of commitment (e.g., the Organizational Commitment Questionnaire).

A possible limitation of this study concerns the nature of the sample. We chose one company in one industry to control for size of organization, industry differences, and a variety of employment practices that might confound the study of individual differences and workplace attitudes. However, by focusing on the health care industry, we may have limited the generalizability of our sample. Although it represented a broad spectrum of occupations within this industry, the educational level was fairly high, the respondents were largely women, and the industry was rather specialized, even within the health care service sector. In addition, although the distribution of individuals at benevolent, entitled, and equity-sensitive points on the equity sensitivity continuum was highly similar to distributions in earlier studies, there may be varied distributions across different industries. These findings must therefore be considered tentative until corroborative evidence is established.

Another possible limitation of our findings is common-methods bias. We employed one type of data collection-mail surveys. In our view, the access thereby gained to data that are viewed as highly personal and sensitive by respondents seemed to offset the risk of common-methods bias. More pragmatically, given the nature and types of individual differences and attitudes examined, we know of no other way to access this information. Hence, although the threat to internal validity remains, until some other method is available we suspect our methods represent the most acceptable manner in which to collect this type of data. Ultimately, further research examining outcomes related to these attitudes will be worthwhile to validate our preliminary findings.

In summary, this study offers some initial understanding of how equity sensitivity and self-efficacy operate together to influence workplace attitudes. We have corroborated previous results involving the equity sensitivity construct (e.g., King \& Miles, 1994), supporting the notion that not all individuals subscribe to traditional equity theory. In addition, this study increases our knowledge of social cognitive theory by examining the impact of equity sensitivity on the relationship between self-efficacy and workplace attitudes. Such advances of these theories are potentially beneficial to those attempting to understand and better predict employee behavior.

\section{References}

Adams, J. S. (1965). Inequity in social exchange. In H. L.Tosi \& W. C.Hamner (Eds.), Organizational behavior and management: A contingency approach (3rd ed., (pp. 209-225). New York: Wiley.

Allen, N. J., \& Meyer, J. P. (1990). The measurement and antecedents of affective, continuance, and normative commitment to the organization. Journal of Occupational Psychology, 63, 1-18.

Bandura, A. (1977). Social learning theory. Englewood Cliffs, NJ: Prentice Hall. 
Bandura, A. (1986). Social foundations of thought and action: A social cognitive theory. Englewood Cliffs, NJ: Prentice Hall.

Bandura, A. (1997). Self-efficacy: The exercise of control. New York: Freeman.

Barling, J., \& Beattie, R. (1983). Self-efficacy beliefs and sales performance. Journal of Organizational Behavior Management, 5, 41-51.

Betz, N. E., \& Hackett, G. (1986). Applications of self-efficacy theory to understanding career and choice behavior. Journal of Social and Clinical Psychology, 4, 279-289.

Brayfield, A. H., \& Rothe, H. F. (1951). An index of job satisfaction. Journal of Applied Psychology, 35, 307-311.

Brockner, J. (1985). The relation of trait self-esteem and positive inequity to productivity. Journal of Personality, 53, 517-529.

Brockner, J., Greenberg, J., Brockner, A., Bortz, J., Davy, J., \& Carter, C. (1986). Layoffs, equity theory, and work performance: Further evidence of the impact of survivor guilt. Academy of Management Journal, 29, 373-384.

Button, S. B., Mathieu, J. E., \& Aikin, K. J. (1996). An examination of the relative impact of assigned goals and self-efficacy on personal goals and performance over time. Journal of Applied Social Psychology, 25, 1084-1103.

Cohen, J., \& Cohen, P. (1983). Applied multiple regression/correlation analysis for the behavioral sciences. Hillsdale, NJ: Erlbaum.

Cook, J. D., Hepworth, S. J., Wall, T. D., \& Warr, P. B. (1981). The experience of work: A compendium and review of 249 measures and their use. London: Academic Press.

DeCotiis, T. A., \& Summers, T. P. (1987). A path analysis of a model of the antecedents and consequences of organizational commitment. Human Relations, 40, 445-470.

Farkas, A. J., \& Tetrick, L. E. (1989). A three-wave longitudinal analysis of the causal ordering of satisfaction and commitment in turnover decisions. Journal of Applied Psychology, 74, 855868.

Ferris, G. R., \& Rowland, K. M. (1987). Tenure as a moderator of the absence-intent to leave relationship. Human Relations, 49, 225-266.

Festinger, L. (1954). A theory of social comparison processes. Human Relations, 7, 117-140.

George, J. M., \& Jones, G. R. (1996). The experience of work and turnover intentions: Interactive effects of value attainment, job satisfaction, and positive mood. Journal of Applied Psychology, 81, 318-325.

Gist, M. E. (1987). Self-efficacy: Implications for organizational behavior and human resource management. Academy of Management Review, 12, 472-485.

Gist, M. E., Stevens, C. K., \& Bavetta, A. G. (1991). Effects of self-efficacy and post-training intervention on the acquisition and maintenance of complex interpersonal skills. Personnel Psychology, 44, 837-861.

Greenberg, J. (1990). Organizational justice: Yesterday, today, and tomorrow. Journal of Management, 16, 399-432.

Greenberg, J., \& Westcott, D. R. (1983). Indebtedness as a mediator of reactions to aid. In J. D.Fisher, A.Nadler, \& B. M.DePaulo (Eds.), New directions in helping, Vol. 1 (pp. 85-122). New York: Academic Press. 
Hatfield, E., \& Sprecher, S. (1983). Equity theory and recipient reactions to aid. In J. D.Fisher, A.Nadler, \& B. M.DePaulo (Eds.), New directions in helping, Vol. 1 (pp. 113-141). New York: Academic Press.

Hom, P. W., \& Griffeth, R. W. (1995). Employee turnover. Cincinnati, OH: Southwestern.

Huseman, R. C., Hatfield, J. D., \& Miles, E. W. (1985). Test for individual perceptions of job equity: Some preliminary findings. Perceptual and Motor Skills, 61, 1055-1064.

Huseman, R. C., Hatfield, J. D., \& Miles, E. W. (1987). A new perspective on equity theory: The equity sensitivity construct. Academy of Management Review, 12, 222-234.

Irving, P. G., Coleman, D. F., \& Cooper, C. L. (1997). Further assessments of a three-component model of occupational commitment: Generalizability and differences across occupations. Journal of Applied Psychology, 82, 444-452.

King, W. C., Jr., \& Miles, E. W. (1994). The measurement of equity sensitivity. Journal of Occupational and Organizational Psychology, 67, 133-142.

King, W. C., Jr., Miles, E. W., \& Day, D. D. (1993). A test and refinement of the equity sensitivity construct. Journal of Organizational Behavior, 14, 301-317.

Lent, R. W., \& Hackett, G. (1987). Career self-efficacy: Empirical status and future directions. Journal of Vocational Behavior, 30, 347-382.

Locke, E. A. (1976). The nature and causes of job satisfaction. In M. D.Dunnette (Ed.), Handbook of industrial and organizational psychology (pp. 1297-1349). Chicago: Rand McNally.

Locke, E. A., Frederick, E., Lee, C., \& Bobko, P. (1984). The effects of self-efficacy, goals, and task strategies on task performance. Journal of Applied Psychology, 69, 241-251.

Locke, E. A., \& Latham, G. P. (1990a). A theory of goal setting and task performance. Englewood Cliffs, NJ: Prentice Hall.

Locke, E. A., \& Latham, G. P. (1990b). Work motivation and satisfaction: Light at the end of the tunnel. American Psychological Society, 1, 240-246.

Major, B., \& Deaux, K. (1982). Individual differences in justice behavior. In J.Greenberg \& R. L.Cohen (Eds.), Equity and justice in social behavior (pp. 43-76). New York: Academic Press.

Mathieu, J. (1991). A cross-level nonrecursive model of the antecedents of organizational commitment and satisfaction. Journal of Applied Psychology, 76, 607-618.

Mathieu, J., \& Zajac, D. (1990). A review and meta-analysis of the antecedents, correlates, and consequences of organizational commitment. Psychological Bulletin, 108, 171-194.

Meyer, J. P., \& Allen, N. J. (1997). Commitment in the workplace: Theory, research and application. Thousand Oaks, CA: Sage.

Meyer, J. P., Allen, N. J., \& Gellatly, I. R. (1990). Affective and continuance commitment to the organization: Evaluation of measures and analysis of concurrent and time-lagged relations. Journal of Applied Psychology, 75, 710-720.

Miles, E. W., Hatfield, J. D., \& Huseman, R. C. (1989). The equity sensitivity construct: Potential implications for worker performance. Journal of Management, 15, 581-588.

Miles, E. W., Hatfield, J. D., \& Huseman, R. C. (1994). Equity sensitivity and outcome importance. Journal of Organizational Behavior, 15, 585-596.

Miner, J. B. (1980). Theories of organizational behavior. Hinsdale, IL: Dryden Press.

Mobley, W. (1977). Intermediate linkages in the relationship between job satisfaction and employee turnover. Journal of Applied Psychology, 62, 237-240. 
Mobley, W. H., Horner, S. O., \& Hollingsworth, A. T. (1978). An evaluation of precursors of hospital employee turnover. Journal of Applied Psychology, 63, 408-414.

Mone, M. A. (1994a). Relationships between self-concepts, aspirations, emotional responses, and intent to leave a downsizing organization. Human Resource Management, 33, 281-298.

Mone, M. A. (1994b). Comparative validity of two measures of self-efficacy in predicting academic goals and performance. Educational and Psychological Measurement, 54, 516-529.

Mone, M. A., \& Baker, D. A. (1992). A social-cognitive, attributional model of personal goals: An empirical evaluation. Motivation and Emotion, 16, 297-321.

Mowday, R. T. (1991). Equity theory predictions of behavior in organizations. In R. M.Steers \& L. W.Porter (Eds.), Motivation and work behavior (5th ed., (pp. 111-131). New York: McGraw Hill.

Mowday, R. T., Porter, L. W., \& Steers, R. M. (1982). Employee-organization linkages: The psychology of commitment, absenteeism, and turnover. New York: Academic Press.

Ostroff, C. (1992). The relationship between satisfaction, attitudes, and performance: An organizational-level analysis. Journal of Applied Psychology, 77, 963-974.

Patrick, S. L., \& Jackson, J. J. (1991). Further examination of the equity sensitivity construct. Perceptual and Motor Skills, 73, 1091-1106.

Pritchard, R. D., Dunnette, M. D., \& Jorgenson, D. O. (1972). Effects of perceptions of equity and inequity on worker performance and satisfaction. Journal of Applied Psychology, 56, 75-94.

Randall, D. M. (1987). Commitment and the organization: The organization man revisited. Academy of Management Review, 12, 460-471.

Reichers, A. E. (1985). A review and reconceptualization of organizational commitment. Academy of Management Review, 10, 465-476.

Spector, P. E. (1997). Job satisfaction: Application, assessment, causes, and consequences. Thousand Oaks, CA: Sage.

Tett, R. P., \& Meyer, J. P. (1993). Job satisfaction, organizational commitment, turnover intention, and turnover: Path analyses based on meta-analytic findings. Personnel Psychology, 46, 259-293.

Wanous, J. P., Reichers, A. E., \& Hudy, M. J. (1997). Overall job satisfaction: How good are single-item measures? Journal of Applied Psychology, 82, 247-252.

Weick, K. E. (1966). The concept of equity in the perception of pay. Administrative Science Quarterly, 11, 414-439.

Wood, R. E., \& Bandura, A. (1989). Impact of conceptions of ability on self-regulatory mechanisms and complex decision making. Journal of Personality and Social Psychology, 56, 407-415.

Wood, R. E., \& Locke, E. A. (1987). The relation of self-efficacy and grade goals to academic performance. Educational and Psychological Measurement, 26, 207-231.

Submitted: August 29, 1997 Revised: April 15, 1998 Accepted: April 20, 1998

This publication is protected by US and international copyright laws and its content may not be copied without the copyright holders express written permission except for the print or download capabilities of the retrieval software used for access. This content is intended solely for the use of the individual user.

Source: Journal of Applied Psychology. Vol. 83. (5), Oct, 1998 pp. 805-816) 
Accession Number: 1998-12528-012

Digital Object Identifier: 10.1037/0021-9010.83.5.805 